\title{
ИЗМЕНЕНИЯ ЧУВСТВИТЕЛЬНОСТИ КЛЕТОК ГЛИОБЛАСТОМ ЧЕЛОВЕКА К ОНКОЛИТИЧЕСКИМ ЭНТЕРОВИРУСАМ ПРИ ПАССИРОВАНИИ В КУЛЬТУРЕ
}

\author{
А. В. Соболева',2, А. В. Липатова', Д. В. Кочетков', П. М. Чумаков ${ }^{1,2}$ \\ ${ }^{1}$ Институт молекулярной биологии имени В. А. Энгельгардта, Москва \\ 2 Федеральный научный центр исследований и разработки иммунобиологических препаратов имени М. П. Чумакова, Москва
}

\begin{abstract}
Современная терапия мультиформных глиобластом не приводит к излечению пациентов. В качестве альтернативы перспективны онколитические вирусы (ОВ): они способны уничтожать опухолевые стволовые клетки, источники рецидивов. Однако каждый отдельный штамм ОВ эффективен только в ряде случаев. Для подбора подходящего штамма требуется тестирование чувствительности на живых опухолевых клетках пациента. Целью исследования было изучение изменения чувствительности к вирусам в процессе пассирования опухолевых клеток пациента в культуре. Органные и первичные культуры клеток глиобластом получали из операционного материала больных. Проводили сравнение чувствительности к четырем штаммам непатогенных энтеровирусов (вакцинный штамм полиовируса 1 типа, вирус Коксаки А7, Эховирусы 1 и 12) на первичных культурах, и на клетках, прошедших около 700 удвоений при пассировании. Чувствительность к вирусам оценивали по измерению доли жизнеспособных клеток с помощью МТT теста через 72 ч после заражения серийными десятикратными разведениями вирусных препаратов. Клетки каждого из четырех пациентов имели строго индивидуальные спектры чувствительности к испытанным вирусным штаммам. Различия в минимальной инфекционной дозе, необходимой для заражения культур, составляли до $10^{5}$. При пассировании происходили изменения в чувствительности, которые могли приводить к повышению чувствительности к одному вирусу, и понижению - к другому. Различия в чувствительности коррелировали со способностью зараженных клеток продуцировать инфекционный вирус. На основании полученных данных можно заключить, что испытание индивидуальной чувствительности опухолевых клеток пациентов следует проводить на как можно более ранних этапах пассирования, предпочтительно — на первичных культурах.
\end{abstract}

Ключевые слова: онколитические вирусы, непатогенные энтеровирусы человека, мультиформная глиобластома, культура клеток, вирусная инфекция, чувствительность к вирусам, вирусный онколиз, виротерапия

Финансирование: работа выполнена при финансовой поддержке Министерства образования и науки РФ, уникальный код проекта RFMEFI60714Х0014.

$\bigotimes$ Для корреспонденции: Петр Михайлович Чумаков

ул. Вавилова, д. 32, г. Москва, 119991; chumakovpm@yahoo.com

Статья получена: 16.06.2018 Статья принята к печати: 22.06.2018

DOI: $10.24075 /$ vrgmu.2018.025

\section{CHANGES IN THE SENSITIVITY OF HUMAN GLIOBLASTOMA CELLS TO ONCOLYTIC ENTEROVIRUSES INDUCED BY PASSAGING}

Soboleva $A V^{1,2}$, Lipatova AV ${ }^{1}$, Kochetkov DV ${ }^{1}$, Chumakov $\mathrm{PM}^{1,2} \otimes$

${ }^{1}$ Engelhardt Institute of Molecular Biology, Moscow

${ }^{2}$ Chumakov Federal Scientific Center for Research and Development of Immune-and-Biological Products, Moscow

Existing therapies for glioblastoma multiforme do not ensure patient's recovery. Oncolytic viruses (OV) represent a promising alternative as they can destroy glioblastoma-initiating stem cells, the major cause of relapses. However, while individual OV strains are effective for some patients, they could be ineffective for others. To achieve a predictable therapeutic effect, live tumor cells of the patient need to be tested for their sensitivity to different viruses. The aim of this study was to assess how sensitivity of tumor cells to viruses changes with passaging in the cell culture. Primary glioblastoma cell cultures were prepared from excised tumors. We compared the sensitivity of the cells to four non-pathogenic enteroviruses (type 1 poliovirus, Coxsackie virus A7, Echoviruses 1 and 12) for freshly explanted primary tumor cell cultures and for those that had undergone 700 divisions during passaging. Cell sensitivity was assessed by the MTT assay based on the proportion of viable cells 72 hours after the cells were inoculated with serial 10-fold dilutions of virus preparations. Cells isolated from the tumors of 3 patients exhibited varying sensitivity to the used viral strains. Differences in the lowest virus dose required for the successful infection of the cell cultures were as high as $10^{5}$. Passaging induced sensitivity shifts, such as increased or decreased sensitivity to individual viruses. Differences in the sensitivity correlated with the ability of the infected cells to produce the virus. Based on our findings, we conclude that the sensitivity of cancer cells to viruses should be tested at very early stages of passaging, preferably in primary cultures.

Keywords: oncolytic viruses, non-pathogenic human enteroviruses, glioblastoma multiforme, cell culture, viral infection, sensitivity to viruses, viral oncolysis, virotherapy

Funding: this work was supported by the Ministry of Education and Science of the Russian Federation (Project ID RFMEFI60714X0014).

$\varangle$ Correspondence should be addressed: Peter M. Chumakov

Vavilova 32, Moscow, 119991; chumakovpm@yahoo.com

Recieved: 16.06.2018 Accepted: 22.06.2018

DOI: $10.24075 /$ brsmu.2018.025 
Мультиформные глиобластомы - наиболее агрессивные опухоли головного мозга, для которых в настоящее время нет эффективной терапии, а средний период выживаемости пациентов после постановки диагноза и проводимого лечения составляет всего 15 месяцев [1, 2]. Трудности терапии глиобластом объясняются слабой проницаемостью через гематоэнцефалический барьер применяемых химиотерапевтических препаратов, а также способностью опухолевых стволовых клеток проникать вглубь здоровой ткани мозга и тем самым избегать хирургического удаления. В последнее время надежды на преодоление тупиковой ситуации с терапией глиобластом связывают с использованием онколитических вирусов. Описаны случаи успешного лечения и длительных многолетних ремиссий при их использовании [3-8]. Более того, установлена возможность уничтожения опухолевых стволовых клеток глиобластом под действием вирусов [9-14]. Однако несмотря на описанные случаи вирусной терапии глиобластом, применение онколитических вирусов оказывается эффективным только для части пациентов. Это связано с различиями молекулярногенетических повреждений в клетках опухолей пациентов, влияющих на чувствительность к отдельным штаммам вирусов. Поэтому для достижения терапевтического эффекта целесообразно использование панелей онколитических вирусов, обладающих перекрывающимся спектром тропизма в отношении разных индивидуальных опухолевых клеток. Одним из подходов к более эффективному использованию вирусов может быть предварительное испытание индивидуальной чувствительности опухолевых клеток пациента к ряду препаратов онколитических вирусов с целью подбора наиболее эффективных вариантов. Для испытания необходимо получить жизнеспособные клетки из удаленного у пациента фрагмента опухоли и пассировать культуры клеток опухоли с целью установления причин их дифференциальной чувствительности к различным вирусам. Для отработки такого подхода мы провели оптимизацию процедуры получения живых клеток из глиобластом, их хранения в жизнеспособном состоянии в условиях глубокой заморозки, а также последующего пассирования в культуре клеток. Основной целью работы было определение, насколько клетки в культуре при их пассировании способны сохранять исходную чувствительность к испытуемому вирусу. В настоящем исследовании мы получили ряд культур клеток от пациентов и сравнили их ответ на заражение несколькими онколитическими энтеровирусами на различных стадиях, начиная от органной первичной культуры, и вплоть до десяти пассажей в культуре.

\section{МАТЕРИАЛЫ И МЕТОДЫ}

\section{Линии клеток мультиформной глиобластомы}

Клетки глиобластом U87MG и A172 из Американской коллекции клеточных культур (АТСС) выращивали в среде DMEM (ПанЭко, Москва) с добавлением 10\% эмбриональной телячьей сыворотки (ЭТC), 4 мM L-глутамина, 100 ед./мл пенициллина, 100 мкг/мл стрептомицина в атмосфере $5 \% \mathrm{CO}_{2}$ и при температуре $37{ }^{\circ} \mathrm{C}$. Первичные органные культуры глиобластом приготовляли из свежих кусочков удаленных опухолей пациентов.

\section{Получение органных и первичных культур глиобластом}

Опухолевый материал получали в НИИ нейрохирургии имени Н. Н. Бурденко, согласно протоколу утвержденному этическим комитетом организации. Образцы опухолевой ткани забирали в стерильные пробирки заполненные питательной средой DMEM и хранили при $+4{ }^{\circ} \mathrm{C}$ не более суток. Для получения органных культур кусочки опухоли промывали фоссатно-солевым бусером, помещали на стерильную чашку Петри и с помощью пинцета и скальпеля удаляли участки некроза и кровеносные сосуды. Для получения клеточной суспензии опухоли продавливали через одноразовые стерильные культуральные нейлоновые сетки с размером отверстий 50 микрон, промывали три раза центрифугированием при $800 \mathrm{~g}$ 5 мин, суспендировали в ростовой среде, аккуратно пипетировали до получения гомогенной взвеси частиц, содержащих отдельные клетки или их агрегаты. Для консервирования жизнеспособных органных культур при температуре жидкого азота суспензию частиц помещали в среду DMEM, содержащую 50\% сыворотки и 7\% диметилсульфоксида, разливали по 1 мл в криопробирки. Замораживание проводили в хорошо изолированном контейнере при температуре $-80^{\circ} \mathrm{C}$ в течение суток, после чего ампулы переносили в жидкий азот. Для получения первичных культур глиобластом после диспергирования и доведения до плотности $2 \times 10^{4}$ частиц в 1 мл ростовой среды DMEM-F12 (ПанЭко, Москва) с добавлением 10\% ЭТС и антибиотиков производили высевание клеток на 6-см культуральные пластиковые чашки Петри и инкубировали в атмоссере $5 \% \mathrm{CO}_{2}$ и температуре $37^{\circ} \mathrm{C}$. Каждые 3 суток проводили замену среды. Рост клеток отмечали два раза в неделю. После образования неплотного монослоя (через 6-15 суток) клетки либо консервировали в жидком азоте, как описано выше, либо пассировали далее.

\section{Пассирование культур глиобластом}

При посеве первичных культур образование устойчивого роста до достижения монослоя наблюдали приблизительно у трети культур. Остальные высеянные клетки прекращали деление, вероятно в связи с отсутствием необходимых условий. Для пассирования выросших культур монослои отмытых клеток обрабатывали раствором трипсина и сажали на новые чашки в соотношении 1:2-1:3. Пассирование продолжали в течение длительного времени, и на каждом пассаже часть клеток подвергали криоконсервированию.

\section{Штаммы онколитических вирусов}

В работе использовали непатогенные штаммы энтеровирусов человека: вакцинный штамм полиовируса 1 типа (Сэбин), вирусы Коксаки А7 (ЖЭВ8), Эховирсу 1 (ЖЭВ4) и Эховирус12 (ЖЭВ7) [4, 15]. Энтеровирусы наращивали в культуре клеток почки африканской зеленой обезьяны Vero путем заражения с множественностью менее 1 БОЕ/ кл. и сбора вирусного урожая через 24 ч. Вирусные титры определяли методом конечных разведений на культурах клеток Vero.

\section{Анализ жизнеспособности клеток после инфицирования вирусами}

96-луночные планшеты с клетками первичных и перевиваемых линий инфицировали 10-кратными серийными разведениями вирусов в диапазоне множественностей от $10^{-5}$ до 1 БОЕ/клетку, в четырех повторах. Адсорбцию вируса проводили в течение 1 ч, далее удаляли вируссодержащую 
жидкость, промывали фосфратно-солевым бусрером и культивировали в ростовой среде с 2\% ЭТС. Через 72 ч определяли жизнеспособность клеток с помощью МТТ теста, пользуясь набором реактивов CellTiter $96^{\oplus}$ NonRadioactive Cell Proliferation Assay (Promega, США) в соответствии с инструкцией производителя.

\section{Анализ вирусной репродукции в инфицированных клетках}

Через 5 суток после заражения в планшетах выбирали лунки, где при минимальной дозе вируса наблюдался полный лизис клеток. После трех циклов замораживания-размораживания супернатанты осветляли центрифугированием (10 мин, 1000 g) и использовали для определения вирусного титра как описано выше.

\section{РЕЗУЛЬТАТЫ ИССЛЕДОВАНИЯ}

Мы измерили чувствительность к нескольким штаммам непатогенных энтеровирусов опухолевых клеток, полученных от трех больных и находящихся на различных уровнях пассирования в культуре. Было проведено сравнение первичных культур глиобластом, а также культур 6 пассажа. Время пассирования составляло около двух месяцев, за которые клетки в культурах успевали пройти около 700 делений. Для определения минимальной дозы вируса, необходимой для эффективного заражения, культуры глиобластом инкубировали с серийными десятикратными разведениями стандартных вирусных препаратов и через 72 ч измеряли жизнеспособность клеток. На рис. 1А представлены просили чувствительности к четырем энтеровирусным штаммам первичных культур клеток, приготовленных из опухолей трех пациентов (обозначены как GM-3564-0, GM-3876-0 и GM-3912-0). В качестве контроля испытывали чувствительность к вирусным штаммам стандартной культуры клеток Vero, на которой эти вирусы регулярно пассируются. На рис. 1Б представлены результаты измерения чувствительности к тем же четырем вирусным штаммам культур клеток глиобластом, прошедших по 6 пассирований в культуре клеток (обозначены как GM3564-6, GM-3876-6 и GM-3912-6). В качестве контроля также была использована линия Vero, чувствительность которой оценена в повторе (Vero-2).

Видно, что чувствительность к четырем штаммам энтеровирусов у трех первичных культур клеток глиобластом существенно различалась. Культура GM-3564 наиболее чувствительна к вирусу Коксаки А7 (инфицируется 10-6. кратным разведением вирусного препарата), менее чувствительна к полиовирусу (инфицируется $10^{-4}$-кратным разведением), и очень слабо чувствительна к Эховирусам 1 и 12 (инфицируется 10-3-кратным разведением). Культура GM-3876 наиболее чувствительна к полиовирусу (инсицируется 10-6-кратным разведением), далее - к вирусу Коксаки A7 (10-5-кратное разведение), Эховирусу 12 (четвертое разведение) и Эховирусу 1 (третье разведение). Культура

A

Б

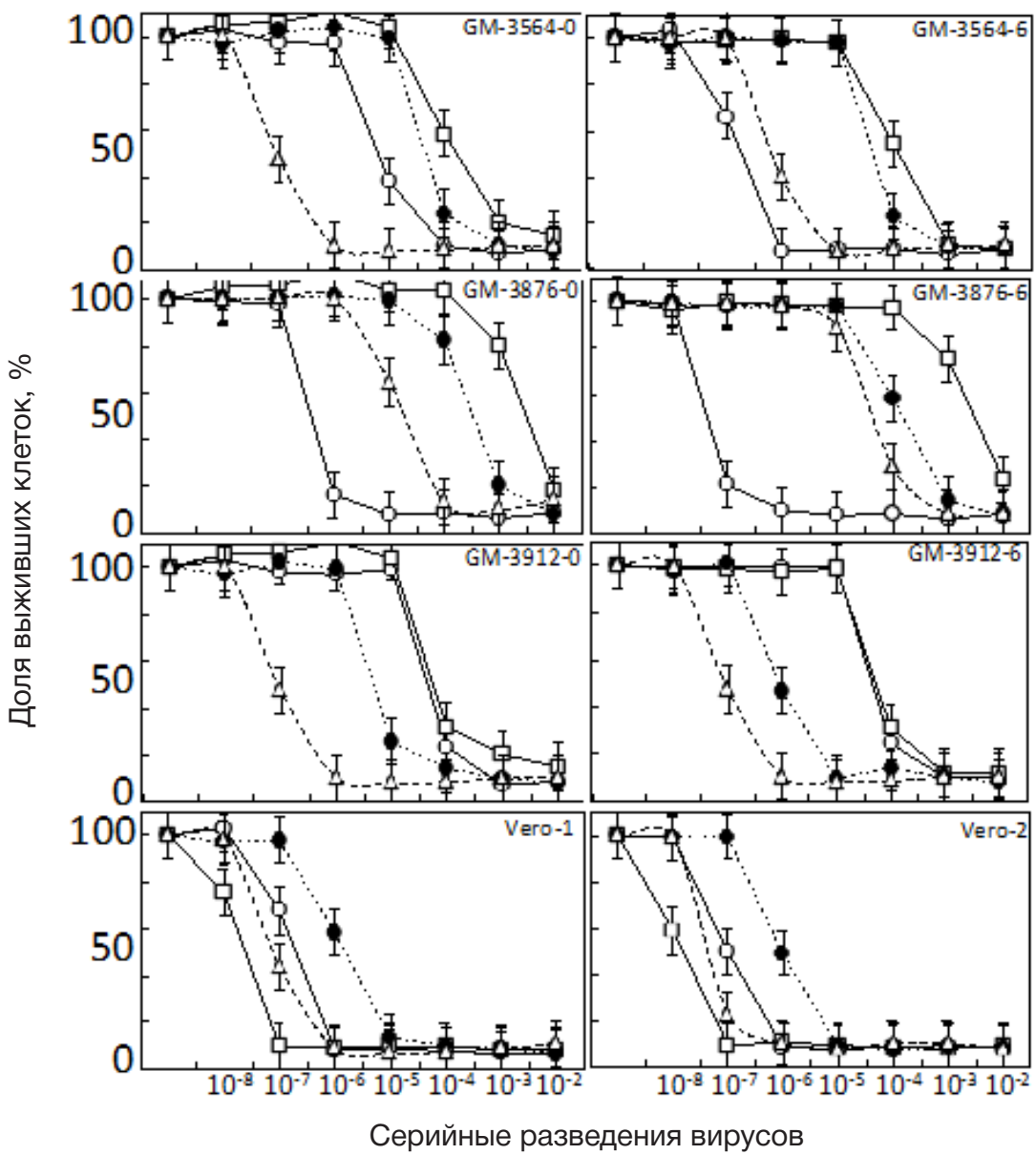

Рис. 1. Чувствительность культур первичных опухолевых клеток глиобластом, полученных от трех пациентов (А), и тех же клеток, прошедших 6 пассажей в культуре (Б), к четырем штаммам непатогенных онколитических энтеровирусов: - О—— полиовирус 1 типа; - - $\Delta$ - - - вирус Коксаки А7; - $\square-$ - Эховирус 1; 
Таблица 1. Инфекционные титры вирусов, продуцируемых первичными и пассированными культурами клеток глиобластом при заражении низкой множественностью (менее 0,001 инфекционных единиц на клетку)

\begin{tabular}{|l|c|c|c|c|}
\hline \multicolumn{1}{|c|}{ Культура клеток } & Полиовирус 1 & Коксаки A7 & Эховирус 1 & Эховирус 12 \\
\hline GM3564-0 & $4 \times 10^{5}$ & $3 \times 10^{7}$ & $5 \times 10^{3}$ & $6 \times 10^{4}$ \\
\hline GM3564-6 & $2 \times 10^{7}$ & $1 \times 10^{7}$ & $6 \times 10^{3}$ & $4 \times 10^{4}$ \\
\hline GM3876-0 & $1 \times 10^{6}$ & $2 \times 10^{4}$ & $1 \times 10^{3}$ & $3 \times 10^{2}$ \\
\hline GM3876-6 & $1 \times 10^{7}$ & $8 \times 10^{3}$ & $2 \times 10^{3}$ & $4 \times 10^{2}$ \\
\hline GM3912-0 & $1 \times 10^{4}$ & $3 \times 10^{7}$ & $8 \times 10^{3}$ & $8 \times 10^{4}$ \\
\hline GM3912-6 & $1 \times 10^{4}$ & $4 \times 10^{7}$ & $8 \times 10^{3}$ & $5 \times 10^{5}$ \\
\hline Vero-1 & $5 \times 10^{7}$ & $8 \times 10^{7}$ & $2 \times 10^{8}$ & $5 \times 10^{6}$ \\
\hline Vero-2 & $4 \times 10^{7}$ & $1 \times 10^{8}$ & $1 \times 10^{8}$ & \\
\hline
\end{tabular}

GM-3912 наиболее чувствительна к вирусу Коксаки A7 (седьмое разведение), далее к полиовирусу (пятое разведение) и Эховирусам 1 и 12 (четвертое разведение). Испытание вирусных препаратов на культуре Vero указывает на наибольшую активность Эховируса 1 (седьмое разведение), далее - полиовируса и вируса Коксаки А7 (шестое разведение) и Эховируса 12 (пятое разведение). Видно, что в результате пассирования произошли качественные изменения чувствительности клеток глиобластом к отдельным вирусам. В клетках GM-3564 произошло повышение чувствительности к полиовирусу 1 типа, и некоторое снижение чувствительности к вирусу Коксаки А7, в то время как чувствительность к Эховирусам 1 и 12 не менялась. В клетках GM-3876 также наблюдалось повышение чувствительности к полиовирусу и снижение чувствительности к вирусу Коксаки А7, и кроме того некоторое повышение чувствительности к Эховирусу 12, при неизменной низкой чувствительности к Эховирусу 1. В клетках GM-3912 наблюдалось лишь некоторое повышение чувствительности к Эховирусу 12 при неизменной чувствительности к остальным трем вирусам.

Различия в чувствительности клеток глиобластом к отдельным вирусам а также наблюдаемые изменения при пассировании могли быть связаны с изменениями репродукции вирусов. Для установления количественных параметров репродукции инфекционных вирусов были определены титры инфекционности в супернатантах культур зараженных предпоследним разведением, вызвавшим цитопатическое действие. Инфекционная доза в предпоследнем разведении составляла около десяти инфекционных единиц на лунку 96-гнездного планшета, что является оптимальной дозой, гарантирующей заражение культуры, и в то же время позволяющей избегать наработку и накопление десектных интерферирующих частиц. В таблице представлены результаты определения инфекционных титров вирусов в каждой из первичных и пассированных культур клеток глиобластом.

Результаты определения титров частиц подтверждают предположение о том что изменения чувствительности $\mathrm{K}$ заражению вирусами в процессе пассирования клеток связаны с более или менее эффективной репликацией того или иного вируса. Так, при пассировании культуры GM3564 репродукция полиовируса возросла более чем в 30 раз, при одновременном трехкратном снижении продукции вируса Коксаки А7 и практически неизменном уровне репликации Эховирусов 1 и 12. Разнообразные изменения спектров чувствительности отмечались и в двух других культурах.

\section{ОБСУЖДДЕНИЕ РЕЗУЛЬТАТОВ}

Мультиформная глиобластома является крайне агрессивной формой опухолей головного мозга. Геном ее клеток очень нестабилен, в связи с чем популяция клеток опухоли постоянно претерпевает изменения и крайне неоднородна. Если в условиях организма за счет действия ряда факторов наблюдается определенный баланс клеточного состава внутри опухоли, то при переводе в культуру часть клеток может прекратить деления. Это приводит к перерастанию отдельных более приспособленных к культивированию in vitro типов опухолевых клеток. В связи с этим можно предположить, что отбор определенных типов клеток в популяции может сопровождаться и изменениями в чувствительности к действию онколитических вирусов.

Полученные в ходе исследования результаты указывают на то что в ходе пассирования первичных опухолей происходят определенные изменения, приводящие $\mathrm{k}$ возрастанию или уменьшению чувствительности к отдельным вирусам. Это может быть связано с исходной гетерогенностью популяции опухолевых клеток, которые по ряду причин могут различаться по чувствительности к вирусам. В культуре происходит перерастание определенного клеточного компонента, в результате чего меняется и общий уровень чувствительности к вирусам.

\section{ВЫВОДЫ}

Проведенное испытание чувствительности к четырем штаммам онколитических энтеровирусов опухолевых клеток от трех больных глиобластомами дает основание сделать вывод, что опухоли исходно обладают индивидуальными спектрами чувствительности к панели вирусов и что при пассировании происходят качественные изменения чувствительности к отдельным вирусным штаммам. Результаты указывают на необходимость проведения тестирований чувствительности к вирусам на самых ранних стадиях перевода клеток в культуру.

\section{Литература}

1. Wen PY, Kesari S. Malignant gliomas in adults. N Engl J Med. 2008; 359 (5): 492-507.
2. Mirimanoff RO, Gorlia T, Mason W, Van den Bent MJ, Kortmann RD, Fisher B, et al. Radiotherapy and temozolomide for newly 
diagnosed glioblastoma: recursive partitioning analysis of the EORTC 26981/22981-NCIC CE3 phase III randomized trial. $\mathrm{J}$ Clin Oncol. 2006; 24 (16): 2563-9. Epub 2006/06/01. DOl: 24/16/2563 [pii] 10.1200/JCO.2005.04.5963. PubMed PMID: 16735709 .

3. Сосновцева А. О., Гриненко Н. Ф., Липатова А. В., Чумаков П. М., Чехонин В. П. Онколитические вирусы в терапии злокачественных глиом. Биомедицинская химия. 2016 (4): 376-90.

4. Губанова Н. В., Гайтан А. С., Разумов И. А., Мордвинов В. А., Кривошапкин А. Л., Нетесов С. В., et al. Онколитические вирусы в терапии глиом. Молекулярная биология. 2012; 46 (6): 726-38.

5. Csatary LK, Bakacs T. Use of Newcastle disease virus vaccine $(\mathrm{MTH}-68 / \mathrm{H})$ in a patient with high-grade glioblastoma. JAMA. 1999; 281 (17): 588-9.

6. Markert JM, Medlock MD, Rabkin SD, Gillespie GY, Todo T, Hunter WD, et al. Conditionally replicating herpes simplex virus mutant, G207 for the treatment of malignant glioma: results of a phase I trial. Gene Ther. 2000; 7 (10): 867-74.

7. Csatary LK, Gosztonyi G, Szeberenyi J, Fabian Z, Liszka V, Bodey B, et al. MTH-68/H oncolytic viral treatment in human highgrade gliomas. J Neurooncol. 2004; 67 (1-2): 83-93.

8. Iwadate $\mathrm{Y}$, Inoue M, Saegusa T, Tokusumi Y, Kinoh H, Hasegawa M, et al. Recombinant Sendai virus vector induces complete remission of established brain tumors through efficient interleukin-2 gene transfer in vaccinated rats. Clin Cancer Res. 2005; 11 (10): 3821-7.

\section{References}

1. Wen PY, Kesari S. Malignant gliomas in adults. N Engl J Med. 2008; 359 (5): 492-507.

2. Mirimanoff RO, Gorlia T, Mason W, Van den Bent MJ, Kortmann RD, Fisher B, et al. Radiotherapy and temozolomide for newly diagnosed glioblastoma: recursive partitioning analysis of the EORTC 26981/22981-NCIC CE3 phase III randomized trial. J Clin Oncol. 2006; 24 (16): 2563-2569. DOI: 10.1200/ JCO.2005.04.5963. PubMed PMID: 16735709.

3. Sosnovtceva AO, Grinenko NF, Lipatova AV, Chumakov PM, Chekhonin VP. Onkoliticheskie virusy v terapii zlokachestvennih gliom. Biomeditsinskaia khimiia. 2016; 62 (4): 376-90. DOI: 10.18097/pbmc20166204376. PubMed PMID: 27562991.

4. Gubanova NV, Gaytan AS, Razumov IA, Mordvinov VA, Krivoshapkin AL, Netesov SV, et al. Onkoliticheskie virusy v terapii gliom. Molecular Biology. 2012; 46 (6): 726-38.

5. Csatary LK, Bakacs T. Use of Newcastle disease virus vaccine (MTH-68/H) in a patient with high-grade glioblastoma. JAMA. 1999; 281 (17): 588-589.

6. Markert JM, Medlock MD, Rabkin SD, Gillespie GY, Todo T, Hunter WD, et al. Conditionally replicating herpes simplex virus mutant, G207 for the treatment of malignant glioma: results of a phase I trial. Gene Ther. 2000; 7 (10): 867-874.

7. Csatary LK, Gosztonyi G, Szeberenyi J, Fabian Z, Liszka V, Bodey B, et al. MTH-68/H oncolytic viral treatment in human highgrade gliomas. J Neurooncol. 2004; 67 (1-2): 83-93.

8. Iwadate $\mathrm{Y}$, Inoue $\mathrm{M}$, Saegusa $\mathrm{T}$, Tokusumi $\mathrm{Y}$, Kinoh H, Hasegawa $M$, et al. Recombinant Sendai virus vector induces complete remission of established brain tumors through efficient interleukin-2
9. Allen C, Opyrchal M, Aderca I, Schroeder MA, Sarkaria JN, Domingo $\mathrm{E}$, et al. Oncolytic measles virus strains have significant antitumor activity against glioma stem cells. Gene Ther. 2012; 23 (10): 62.

10. Alonso MM, Jiang H, Gomez-Manzano C, Fueyo J. Targeting brain tumor stem cells with oncolytic adenoviruses. Methods Mol Biol. 2012; 797: 111-25.

11. Dey M, Ulasov IV, Lesniak MS. Virotherapy against malignant glioma stem cells. Cancer Lett. 2010; 289 (1): 1-10.

12. Kanai R, Rabkin SD, Yip S, Sgubin D, Zaupa CM, Hirose Y, et al. Oncolytic virus-mediated manipulation of DNA damage responses: synergy with chemotherapy in killing glioblastoma stem cells. J Natl Cancer Inst. 2012; 104 (1): 42-55.

13. van den Hengel SK, Balvers RK, Dautzenberg IJ, van den Wollenberg DJ, Kloezeman JJ, Lamfers ML, et al. Heterogeneous reovirus susceptibility in human glioblastoma stem-like cell cultures. Cancer Gene Ther. 2013; 20(9): 507-13. Epub 2013/08/03. DOI: 10.1038/cgt.2013.47. PubMed PMID: 23907517.

14. Zhu Z, Gorman MJ, McKenzie LD, Chai JN, Hubert CG, Prager BC et al. Zika virus has oncolytic activity against glioblastoma stem cells. J Exp Med. 2017; 214 (10): 2843-57. Epub 2017/09/07. doi: 10.1084/jem.20171093. PubMed PMID: 28874392; PubMed Central PMCID: PMCPMC5626408.

15. Voroshilova MK. Potential use of nonpathogenic enteroviruses for control of human disease. Prog Med Virol. 1989; 36: 191-202. Epub 1989/01/01. PubMed PMID: 2555836. gene transfer in vaccinated rats. Clin Cancer Res. 2005; 11 (10): 3821-27.

9. Allen C, Opyrchal M, Aderca I, Schroeder MA, Sarkaria JN, Domingo E, et al. Oncolytic measles virus strains have significant antitumor activity against glioma stem cells. Gene Ther. 2012; 23 (10): 62.

10. Alonso MM, Jiang H, Gomez-Manzano C, Fueyo J. Targeting brain tumor stem cells with oncolytic adenoviruses. Methods Mol Biol. 2012; 797: 111-125.

11. Dey M, Ulasov IV, Lesniak MS. Virotherapy against malignant glioma stem cells. Cancer Lett. 2010; 289 (1): 1-10.

12. Kanai R, Rabkin SD, Yip S, Sgubin D, Zaupa CM, Hirose Y, et al. Oncolytic virus-mediated manipulation of DNA damage responses: synergy with chemotherapy in killing glioblastoma stem cells. J Natl Cancer Inst. 2012; 104 (1): 42-55.

13. van den Hengel SK, Balvers RK, Dautzenberg IJ, van den Wollenberg DJ, Kloezeman JJ, Lamfers ML, et al. Heterogeneous reovirus susceptibility in human glioblastoma stem-like cell cultures. Cancer Gene Ther. 2013; 20(9): 507-513. DOI: 10.1038/ cgt.2013.47. PubMed PMID: 23907517.

14. Zhu Z, Gorman MJ, McKenzie LD, Chai JN, Hubert CG, Prager BC, et al. Zika virus has oncolytic activity against glioblastoma stem cells. J Exp Med. 2017; 214 (10): 2843-57. DOI: 10.1084/ jem.20171093. PubMed PMID: 28874392; PubMed Central PMCID: PMCPMC5626408.

15. Voroshilova MK. Potential use of nonpathogenic enteroviruses for control of human disease. Prog Med Virol. 1989; 36: 191-202. PubMed PMID: 2555836 